"This is an Author's Accepted Manuscript of an article published in online in International Journal of Health Economics and Management in May 2018. The final publication is available at https://doi.org/10.1007/ s10754-018-9244-1". 


\title{
Switching benefits and costs in the Irish health insurance market: An analysis of consumer surveys
}

\author{
Conor Keegan • Conor Teljeur • Brian \\ Turner • Steve Thomas
}

Received: date / Accepted: date

\begin{abstract}
Relatively little analysis has taken place internationally on the consumer-reported benefits and costs to switching insurer in multi-payer health insurance markets. Ideally, consumers should be willing to switch out of consideration for price and quality and switching should be able to take place without incurring significant switching costs. Costs to switching come in many forms and understanding the nature of these costs is necessary if policy interventions to improve market competition are to be successful. This study utilises data from consumer surveys of the Irish health insurance market collected between 2009 and $2013(\mathrm{~N}=1,703)$ to examine consumer-reported benefits and costs to switching insurer. Probit regression models are specified to examine the relationship between consumer characteristics and reported switching costs, and switching behaviour, respectively. Overall evidence suggests that switchers in the Irish market mainly did so out of consideration for price. Transaction cost was the most common switching cost identified, reported by just under 1 in 7 non-switchers. Psychological switching costs may also be impacting behaviour. Moreover, high-risk individuals were more likely to experience switching costs and this was reflected in actual switching behaviour. A recent informational campaign launched by the market regulator may prove beneficial in reducing perceived transaction costs in the market, however, a more focused campaign aimed at high-risk consumers may be necessary to reduce inequalities. Policy-makers should also consider the impact insurer behaviour may have on decision-making.
\end{abstract}

C. Keegan

Economic and Social Research Institute

Whitaker Square

Sir John Rogerson's Quay

Dublin 2.

Tel.: +353-1-8632129

E-mail: conor.keegan@esri.ie 
Keywords Health insurance markets - Switching benefits - Switching costs · Irish health system

\section{Introduction}

In multi-payer health insurance markets, it is well recognised that the dynamics of consumer mobility can provide key insights into understanding the competitive environment in which these markets operate [58,44,4]. Particularly, individuals should be willing to switch out of price and quality concerns to motivate insurers to compete along these parameters. However, costs to switching also exist and these will also influence decision making [15]. High switching costs can weaken competitive forces and inequalities can arise if certain groups are more likely to experience these costs. Traditionally, however, focus has been on understanding the determinants of actual switching behaviour. Additional insights, however, can be gleaned from understanding consumer-reported benefits and costs to switching. Particularly, costs to switching come in many forms and in order to identify policy interventions to improve market competitiveness it is necessary to understand the relative importance consumers attach to these costs and their distribution across insured populations.

In this context, the focus of this study is threefold. Specifically, using the Irish private health insurance market as the setting, this study hopes to 1) identify the main benefits and costs to switching insurer 2) determine whether the costs of switching differ between groups of consumers and 3 ) determine whether the observed distribution of switching costs is reflected in actual switching behaviour.This paper contributes to the existing literature in the following ways. First, analysis of consumer-reported switching costs and benefits in health insurance markets has been very limited to date, and mainly concentrated on the Dutch health system $[15,51,33]$. Very little is known about this topic in other settings. This study expands our understanding by providing results from a new institutional environment, the voluntary Irish private health insurance market. Additionally, this paper uses a novel approach of employing a multivariate probit model to analyse the determinants of consumer responses to switching motivations. This estimation technique addresses the problem that individuals may possess unobservable characteristics that are correlated across responses which can lead to in-consistent parameter estimates [10].

Section 2 reviews the conceptual and empirical literature on switching benefits and costs. Section 3 provides and overview of the Irish health insurance market. Section 4 introduces the data and methods. Section 5 and 6 present and discuss the results, respectively. Section 7 concludes.

\section{Literature Review}

Underlying standard consumer-decision making theory is the idea that consumers are rational utility-maximising agents who operate on the basis of full 
and relevant information [60]. Conceptually, therefore, consumers will switch insurer if the benefits of doing so outweigh the costs [44]. Along these lines, a significant body of research exists, across a number of health insurance systems, that shows switchers are price-sensitive $[8,14,52,18,54,19,50,6,35]$. Quality, considered a more complex and multi-dimensional concept, has also been shown to predict consumer choice in both the US and Netherlands [41, 6]. However, other studies suggest that Dutch consumers do not value quality as a switching benefit $[15,51]$. Supplementary insurance benefits (in markets where they exist) and gifts may also be considered switching benefits [15].

Switching rates in health insurance markets tend to be quite low [44], and this may partly be a reflection of the level of switching costs faced by consumers [19]. Particularly, observed differences in switching propensities are often explained in that, cet par, low-risk individuals are thought to face lower switching costs than their high-risk counterparts [16].

For instance, evidence would suggest that younger, wealthier ${ }^{1}$ and more educated consumers tend to have higher switching propensities across a number of settings $[2,7,47,33,6,19,58,51,16,35]$. Evidence related to the relationship between health status and switching propensity is slightly more nebulous. Some studies have reported no relationship $[51,16]$, however, many others suggest that better health is independently and positively associated with switching $[47,33,6,35]$. Although women are generally taken to utilise more healthcare than men [3], evidence on gender effects in switching behaviour is inconsistent $[2,7,47,33,6,19]$.

Previous literature has identified a range of costs potentially faced by consumers when switching firms [38,39,17]. Particularly, Duijmelinck et al [16] recently provided a conceptual outline of switching costs directly relevant to health insurance markets. Based on this literature a number of relevant costs to switching can be identified;

- Search/evaluation costs - relate to the entire time spent identifying and interpreting a firm's product regardless of whether a purchase is made. Search costs can be incurred multiple times [61].

- Transaction costs - relate to the time and effort, particularly administrative, involved in switching insurer.

- Uncertainty costs - relate to the lack of certainty associated with alternative insurer performance.

- Learning costs - relate to the time and effort learning about the policies and procedures of a new insurer (e.g. claims processing).

- Benefit-loss costs - relate to the benefits foregone switching to a new insurer (e.g. in markets where basic and supplementary insurance is closely tied, consumers may lose favourable supplementary insurance benefits if they switch).

\footnotetext{
1 One notable exception is the Israeli health insurance system where switching is found to be an inferior good - those with higher labour-income were found to be less likely to switch [56].
} 
- Provider switching costs - where selective contracting takes place, costs may arise through severing relationships with existing healthcare providers if they are not contracted with the new insurer.

- Psychological costs - It is important, however, to acknowledge that standard consumer-decision theory does not explain all observable behaviour. Particularly, consumers may face a number of psychological (i.e. irrational) costs as part of their decision-making which need to be taken into account. Such bias can manifest in concepts such as loss aversion, status-quo bias, endowment and loyalty effects $[34,53,21,48,32]$.

In terms of search costs, evidence suggests that consumer decision-making deteriorates when confronted with too much choice $[46,57,9,13,20]$. Notably, Frank and Lamiraud [19] found that as the choice set offered to consumers in the Swiss health insurance system increased, their willingness to switch declined. Empirically, Duijmelinck et al [15] report that 'benefit-loss' costs and psychological costs are the most prevalent in the Dutch health insurance system. Psychological costs have also be shown to manifest in terms of statusquo bias, leading to sub-optimal decision-making [5, 42,45]. Along similar lines, longer tenure of enrolment has been shown to reduce the likelihood of switching between plans in the Swiss health insurance system [19]. In line with the review of evidence of switching behaviour presented above, switching costs have been shown to burden high risk individuals to a greater extent $[15,45,51]$.

It is also important to make the distinction between the exogenous and endogenous nature of switching costs. On the one hand, switching costs may be exogenous, and experienced largely regardless of any behaviour by firms. Good examples of such costs may relate to certain psychological costs of switching. In contrast, endogenous switching costs relate to costs that are influenced by firm behaviour [55,17]. For instance, firms may use marketing, product design or promotional offers to artificially manipulate costs faced by consumers. This type of behaviour may be particularly relevant to health insurance markets where it may be possible to earn predictable profits by focusing resources on attracting low-risk cohorts of consumers.

\section{The Irish voluntary health insurance system}

The Irish health system is predominantly government-financed, accounting for $69 \%$ of total health expenditure in 2014 [12]. However, despite publicly-funded access to hospital care, approximately $46 \%$ of the population choose to purchase voluntary private health insurance [26]. The benefits of private health insurance relate mainly to faster access to elective hospital services along with a greater choice of providers and accommodation. Private health insurance plans can provide cover for non-acute services, such as GP and physiotherapist services, but tend to reimburse only part of the cost. Private health insurance therefore mainly fulfils a duplicative role (for hospital care) with some elements of complementarity (limited cover for some primary care services which are not publicly-funded for all residents). As a result, despite a 
large number of plans available on the market (around 200 in 2012 [59]) differences between plans largely stem from differences in access to types of hospital accommodation[1]. Broadly speaking, privately-insured care takes place on a semi-private ${ }^{2}$ or private room basis in either public or private hospitals ${ }^{3}$. All insurers sell a variety of plans for different levels of hospital cover. Other variation in plan design tend to be relatively minor and often stem from market segmentation strategies by insurers to channel low and high risk consumers into different products [59]. For instance, the HIA notes that one way insurers engage in risk selection is through offering lower cost products with reduced orthopaedic benefits in private hospitals, which few older consumers tend to purchase [24]. Individual and multiple-persons plans can be purchased with discounts available for students and children.

The insurance market is heavily regulated operating under lifetime community rating (which replaced a largely single-rate design in May 2015 to address adverse selection issues [27]), open enrolment, lifetime cover and minimum benefit regulations. Despite community rating restrictions, only recently (in 2013) have risk equalisation payments commenced ${ }^{4}$. These replaced a basic system of additional age-related tax credits introduced in 2009. Recent evidence suggests that despite the introduction of risk equalisation, incentives for risk selection remain in the market [36]. The market is populated by four insurers, with the Vhi commanding the largest market share (50.8\%) [31].

Health insurance contracts are generally one year in length and at each renewal period consumers are entitled to renew their current contract, switch plan or insurer, or exit the market entirely. All insurers allow a 14-day cooling off period from renewal dates whereby consumers may still cancel and get a full refund but impose penalties after this point [29]. Individuals with pre-existing conditions may switch plan or insurer without a break in cover. However, if an individual switches to a new plan with higher cover there may be additional waiting periods in respect of the extra benefits associated with the higher cover [28]. Switching plan or insurer in the Irish market is a straightforward process and 'can be accomplished easily in a matter of minutes, by means of two phone calls or online' [11, pg. 72$]$. In an effort to aid consumer decisionmaking, the market regulator, the Health Insurance Authority (HIA), provides publicly available plan comparison and switching information on its website (www.hia.ie).

\footnotetext{
2 This relates to multi-occupancy private rooms

3 However, since January 2014 it can also take place in a ward setting in public hospitals

4 While risk equalisation had previously been introduced to the market in 2003, payments never actually took place due to a successful legal challenge taken by a former market insurer (BUPA) [59].
} 


\section{Data and Methods}

\subsection{Data}

This study is based on market-wide cross-sectional consumer survey data obtained from the HIA collected in 2009, 2011 and 2013, respectively [22, 23, 25]. Data for all years were collected by means of face-to-face interviews. Analysis was restricted to those respondents who reported having private health insurance cover in the year of survey and data for all years were pooled $(\mathrm{N}=1,703)$. Surveys included data on socio-demographic profiles, self-assessed health, prior healthcare utilisation, history of insurer switching, questions related to motivations for (not) switching and questions related to understanding of rules and regulations governing the market. In order to ensure a representative sample of the adult population in the Republic of Ireland (aged 18+) quotas were set around sex, social class and region. The raw data were weighted to reflect the national population.

\subsection{Methods}

In order to understand the motivations for switching and not switching in the market, focus was placed on two specific questions asked to those with private health insurance. These related to:

1. 'Reasons for switching private health insurance provider?'

2. 'Reasons for not switching private health insurance provider?'

For each question, respondents were given a range of non-mutually exclusive responses to consider. In terms of the first question we only considered responses for those who could be identified as switching in the last four years (the most disaggregated breakdown calculable) ${ }^{5}$. The second question was asked to all those who never switched insurer $(\mathrm{N}=1,301)$. In order to determine more dominant benefits and costs, responses to both questions were ranked in terms of frequency, based on weighted percentages. In terms of 'reasons for not switching', it was possible to match a number of responses to actual switching costs identified in Section 2 (see Table 1).

Second, a multivariate probit model was estimated to determine if certain groups of non-switchers were more likely to report these switching $\operatorname{costs}^{6}$. Given that the questions on switching costs are multi-response there may be unobservable individual-level factors that are correlated across equations. The multivariate probit model (estimated using the mvprobit command in Stata 13) accounts for this correlation resulting in consistent estimation. A 5-equation multivariate probit model is estimated, taking the following form,

\footnotetext{
5 This is a derived variable calculated by combining information on switching and consumers' length of time with their current insurer.

6 As the number of switchers was low, it was not possible to perform reliable regression analysis to see if responses related to reasons for switching differed between groups.
} 
Table 1 Reasons for not switching insurer and associated type of switching cost

\begin{tabular}{ll}
\hline Reason for not switching insurer & Associated switching cost \\
\hline 'Too much hassle/paperwork' & Transaction cost \\
'Couldn't be bothered' & Psychological cost \\
'Feel loyal to my current provider' & Psychological cost \\
'Too difficult to compare plans' & Search cost \\
'Concerned that coverage would not be the same' & Uncertainty cost \\
\hline
\end{tabular}

$$
Y_{m}^{*}=\alpha_{m}+\sum_{k=1}^{6} \beta_{k m} X_{k}+\delta_{m} Z+e_{m}, m=1 \ldots 5
$$

where,

$$
Y_{m}= \begin{cases}1 & \text { if } Y_{m}^{*}>0 \\ 0 & \text { otherwise }\end{cases}
$$

$Y_{m}$ represent the 5 binary switching cost variables (identified in Table 1 coded as 1 if a respondent experienced the $m^{\text {th }}$ switching cost and zero otherwise). $X_{k}$ represent the set of consumer and plan characteristics (common to all equations) and $Z$ is a variable capturing the year of survey.

Errors $e_{m}$ follow a multinormal distribution with zero mean and a variancecovariance matrix with values of 1 on the main diagonal and correlation coefficients $\rho_{j k}=\rho_{k j}(j \neq k)$ as off-diagonal elements.

The likelihood function of this high-dimensional multivariate normal distributions is estimated through a simulated maximum likelihood procedure. Specifically, this takes the form of the Geweke-Hajivassiliou-Keane (GHK) simulator. The accuracy of results will depend on the number of random draws used in the calculations [10]. Cappellari and Jenkins [10] suggest setting the number of draws at least equal to the square root of the sample size. Consequently, we set the number of draws at 40. Finally, a basic single-equation probit regression is also estimated to examine the relationship between consumer characteristics and actual switching behaviour.

\section{Results}

Table 2 reports a descriptive summary of the variables of interest disaggregated by year of survey and in terms of weighted and unweighted percentages. Just over nineteen percent of the overall (weighted) sample were aged $65+$, and there was an even split between male and female respondents. Furthermore, the majority of respondents belonged to 'ABC1' (57.4\%) social grade, indicating that it is those from higher socio-economic classes that generally purchase health insurance. The proportion of respondents considering themselves in 'Excellent' health fell over time, with just over half (51\%) reporting themselves in this category. More than one adult was recorded on just over $71 \%$ of plans, 
Table 2 Percentage (unweighted percentage) breakdown of consumer and plan characteristics by year of survey

\begin{tabular}{llllll}
\hline & & $\begin{array}{l}2009 \\
(\mathrm{~N}=480)\end{array}$ & $\begin{array}{l}2011 \\
(\mathrm{~N}=424)\end{array}$ & $\begin{array}{l}2013 \\
(\mathrm{~N}=799)\end{array}$ & $\begin{array}{l}\text { Total } \\
(\mathrm{N}=1,703)\end{array}$ \\
\hline Age & $18-44$ & $49.7(51.3)$ & $45.2(44.6)$ & $43.7(42.2)$ & $45.7(45.3)$ \\
& $45-64$ & $35.4(34.8)$ & $33.9(37.5)$ & $35.8(41.6)$ & $35.2(38.6)$ \\
& $65+$ & $14.9(14)$ & $20.9(17.9)$ & $20.6(16.3)$ & $19.1(16)$ \\
Sex & Male & $49.4(49.2)$ & $51(48.8)$ & $49.8(47.8)$ & $50(48.4)$ \\
& Female & $50.6(50.8)$ & $49(51.2)$ & $50.2(52.2)$ & $50(51.6)$ \\
Social Grade & CBC1 & $55.3(54)$ & $59.3(65.8)$ & $57.7(63.1)$ & $57.4(61.2)$ \\
& F & $34.6(37.1)$ & $32.4(28.8)$ & $33.4(29.8)$ & $33.5(31.6)$ \\
Health Status & Excellent & $56.6(56.5)$ & $49.7(49.1)$ & $48.4(48.3)$ & $51(50.8)$ \\
& Good & $27.8(27.5)$ & $30.3(30.9)$ & $29.3(29.9)$ & $29.2(29.5)$ \\
More than one & Yes & $15.5(16)$ & $19.9(20)$ & $22.3(21.8)$ & $19.8(19.7)$ \\
$\begin{array}{l}\text { adult on plan } \\
\text { One or more }\end{array}$ & Yes & $40.3(69.6)$ & $73.7(69.8)$ & $71.2(72.5)$ & $71.6(71.0)$ \\
$\begin{array}{l}\text { children on plan } \\
\text { Switched within } \\
\text { the last 4 years }\end{array}$ & Yes & $7.3(7.3)$ & $14.9(15.6)$ & $12.9(13.4)$ & $11.8(12.2)$ \\
\hline
\end{tabular}

Table 3 Top 5 reasons for switching insurer (switched in the last 4 years, weighted percentages)

\begin{tabular}{ll}
\hline Reason & Total (\%) \\
\hline New insurer was cheaper/Cost savings & 70.7 \\
Level of cover was better & 20.7 \\
New insurer had a better product/service range & 11.8 \\
Group scheme switched & 7.0 \\
Recommendation from family member & 4.9 \\
\hline
\end{tabular}

while one of more children were present on just over $35 \%$ of plans. In total, just under $12 \%$ of respondents switched in the last four years.

\subsection{Reasons for switching insurer}

Table 3 presents the five most frequently cited reasons for switching insurer. As expected, cost savings was by far the most influential reason for switching, cited by $70.7 \%$ overall. Quality, as proxied by 'level of cover' was the next most frequent response, cited by $20.7 \%$ overall. Another proxy for quality 'newer insurer had a better product/service range' was cited by $11.8 \%$, overall. 'Group scheme switched' $(7.0 \%)$ and 'recommendation from family member' $(4.9 \%)$ made up the remainder of responses. 
Table 4 Reasons for not switching insurer (weighted percentages)

\begin{tabular}{ll}
\hline Reason & Total (\%) \\
\hline Satisfied with current provider & 40.6 \\
Level of cover no better & 14.5 \\
Too much hassle/paperwork & 14.5 \\
Couldn't be bothered & 11.2 \\
Range of products/services no better & 10.0 \\
Not my decision & 9.1 \\
Feel loyal to my current provider & 8.3 \\
Been with existing provider for a long time & 8.3 \\
Work/employer looks after it & 7.9 \\
Don't know & 7.7 \\
Too difficult to compare plans & 7.2 \\
Concerned that coverage would not be the same & 5.7 \\
\hline
\end{tabular}

\footnotetext{
a Truncated at positive responses greater than $5 \%$.

b Responses in italics indicate identified switching costs included in the probit regressions. 'Been with my existing provider for a long time' was not considered due to endogeneity concerns.
}

\subsection{Reasons for not switching insurer}

Table 4 reports on consumer reasons for not switching insurer. Chiefly, respondents did not switch because they were 'satisfied with their current provider', cited by $40.6 \%$, overall. However, certain individuals were discouraged from switching due to perceived lack of product and service differentiation between insurers. $14.5 \%$ cited 'level of cover no better' and 10.0\% cited 'range of products/services no better' as reasons for not switching insurer.

Certain switching costs could also be identified as popular reasons for not switching. Particularly, 'too much hassle/paperwork' (14.5\%) and 'couldn't be bothered' $(11.2 \%)$ were the third and fourth most common reasons for not switching insurer. As outlined in Table 1, these relate to transaction and psychological costs, respectively. Other psychological costs of switching were also identified. 'Feel loyal to my current provider' and 'been with existing provider for a long time' were cited by $8.3 \%$ of respondents. Explicit search costs seem to play slightly less of a role. 'Too difficult to compare plans' was cited by $7.2 \%$ of respondents. Finally, uncertainty costs, manifested in terms of 'concerned that coverage would not be the same' were only cited by $5.7 \%$ of non-switchers as a reason for not switching.

Table 5 presents results for the multivariate probit model. While no common associations are observable across all switching costs, some trends do emerge. Particularly, older and sicker consumers, respectively, appear to perceive higher switching costs than their younger and healthier counterparts. Compared to those aged 18-44, those aged 45-64 ( $\mathrm{p}<0.05)$ were more likely to cite 'too much hassle/paperwork' as a reason for not switching. Similarly, those with 'bad' self-reported health status were more likely to find it difficult 
to compare plans $(\mathrm{p}<0.05)$. Apathy towards the switching decision ('couldn't be bothered') was more likely to be cited by those in worse self-reported health states $(\mathrm{p}<0.05)$. While older individuals were more likely to experience loyalty towards their current provider $(\mathrm{p}<0.01)$. Finally, there is some evidence that while having one or more adults on a plan may reduce the likelihood of reporting certain switching costs, having one or more children on a plan does not impact on switching costs.

The overall distribution of these consumer-reported switching costs is also presented in Figure 1. The overall joint probability of not reporting a switching cost in our sample is $60.8 \%$. However, those who are older and in worse health status, respectively, were significantly less likely not to report a switching cost.

Reflecting these findings, being older, or in bad self-perceived health, were both negatively associated with switching insurer. On average, those aged $65+$ were 4.9 percentage points less likely to switch than those aged $18-44$ (p $<0.05$ ), relative to a (weighted) baseline switching rate of $11.8 \%$. Similarly, those with 'Bad' self-perceived health status were 4.4 percentage points less likely to switch relative to those with 'Excellent' self-perceived health status. 


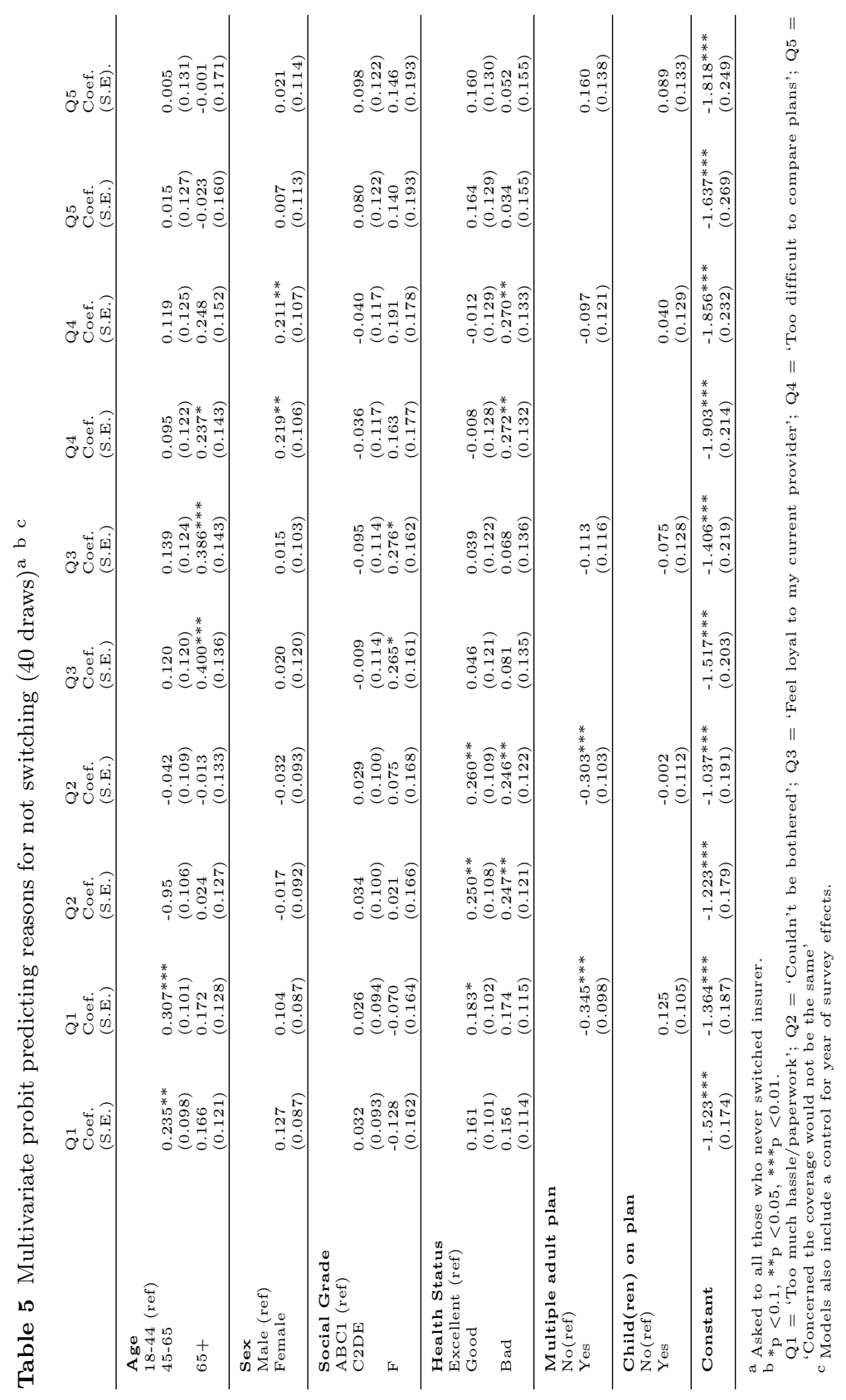




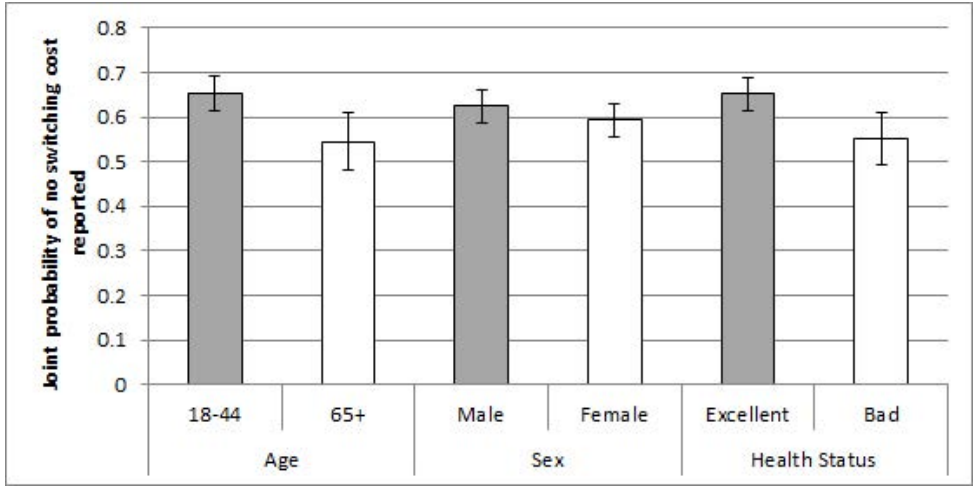

Fig. 1 Joint probability of no switching cost reported (95\% confidence intervals). The joint probability is defined as $\operatorname{Pr}\left(y_{1}=0, y_{2}=0, y_{3}=0, y_{4}=0, y_{5}=0\right)$.

\section{Discussion}

Switching rates in and of themselves may not provide a good insight into the dynamics of market competition. For instance, even a small amount of switching in a contestable market environment may be sufficient to facilitate competitive behaviour while too much switching may be undesirable as it can result in high administrative costs [16]. However, more understanding can be gained from analysing the motivations for switching and whether significant barriers to switching exist.

\subsection{Switching benefits}

As such, an important requirement of competitive health insurance markets is that price and quality considerations guide consumer demand. Therefore, a salient finding is that consumers in the Irish market do appear to be strongly motivated by price considerations. As described in Section 2, this agrees with previous findings in the Irish system and other systems internationally. Quality, in contrast, both in terms of level of cover and also product and service range, motivated switching to a much lesser degree than price. As a consequence, there may be less reason for insurers to compete along these quality parameters.

\subsection{Switching costs}

A large proportion of consumers appear satisfied with their insurance offering and may not switch for that reason. This reflects findings in the Swiss health insurance system where 79 per cent of consumers reported remaining with their health plan due to satisfaction with their current insurance arrangement [19]. 
However, our results suggest that switching costs may be acting as an impediment to ease of switching in the Irish market. Particularly, transaction costs were identified as the most prominent switching cost in the market, cited by just under 1 in 7 non-switchers as a reason for not switching. In contrast, only between $4-6 \%$ of non-switchers in the Dutch system identified administration and transaction costs as a reason for not switching [15,51]. As switching insurer at time of renewal can be considered a relatively straightforward process in the Irish system, this cost may therefore be more perceived than actual. Although the HIA does provide information on the switching process there appears to be a degree of friction between the availability of this information and consumers' use of it [40]. For instance, in 2013, $61 \%$ of the insured population had either no knowledge of the HIA or were aware of the HIA but were unaware of its functions [25]. Interventions to improve consumer awareness of the HIA and information on the switching process may therefore prove worthwhile in reducing perceived transaction costs in the market. In this regard, an information campaign launched by the HIA in November 2016 represents a positive development [30].

Given the large number of plans on the market for consumers to choose from, it is perhaps surprising that consumers do not consider difficulty in plan comparison as more of a major switching barrier. Despite the large number of plans, however, the important dimensions of plan choice perhaps centre on level of hospital cover and price - two easily comparable plan dimensions. As noted, many plans differ based on other relatively minor characteristics and consumers may place less weight on these factors (if any) in their decisionmaking. Another explanation is that the provision of comparative plan information by the HIA may be facilitating easier comparison across the many plans on the market. However, as noted above, many consumers appear unaware of the HIA as a source of this information and therefore this may be unlikely.

Some evidence of possible psychological switching costs were observed. Just under one-in-nine non-switchers cited apathy towards the switching process as a reason for not switching. In reality this apathy may be indicative of other switching barriers [11]. For instance, if transaction costs are high, consumers may see little value in engaging with the switching process. Loyalty to current insurer was also identified as a relevant psychological switching cost. We consider loyalty to be a psychological switching barrier in the Irish system as economic incentives (for instance gifts or discounts) for loyalty are not features of the Irish system. However, this may not be the case in all health insurance systems where loyalty to an existing insurer may be considered more of a rational response.

The level of psychological switching costs identified in the Irish market may not be excessive. However, psychological switching costs, if they exist, can create problems for policy-makers looking to improve behaviour as it is difficult to design interventions to address these costs. For instance, it may be challenging to encourage switching for individuals who are loyal to their 
current insurer and refuse to consider contracting with alternative insurers.

Differences between groups

From a competitive perspective it is also important to consider if reasons non-switchers do not switch, differ between groups. In this context, evidence suggests that overall, high-risk consumers are more likely to experience barriers to switching than their low-risk counterparts. This is also reflected in actual switching behaviour. Older individuals and those with worse self-reported health status were less likely to switch. Similar findings are common among many other health insurance systems and are generally explained in terms of these individuals facing higher costs to switching $[15,43]$.

In terms of these costs, older individuals were more likely to experience loyalty towards their current insurer. In this context, it could be the case that as individuals age their values change and they may be more likely to exhibit such behaviour. Over time it could also be the case that individuals build up a relationship or bond with their insurer, making it more difficult to switch. Alternatively, older individuals are perhaps simply more conservative and, consequently, may be less willing to switch [49].

Although difficulty with plan comparison is not a frequently cited switching cost overall, older and sicker individuals appear more likely to experience it. As an explanation, older and sicker individuals may inherently find plan comparison more difficult. However, these individuals may also place a higher weight on more complex plan dimensions (other than price) such as the technicalities of depth and breadth of coverage. This may increase difficulty of plan comparison. The fact that those in worse health are more likely to display apathy towards the switching process may partly reflect this difficulty ${ }^{7}$. Further investigation, therefore, may be warranted to see if improving these individuals' awareness of, and ability to comprehend, plan comparison information could help reduce inequalities in the market.

Finally, it is important also to be cognisant of the role insurers may play in influencing the distribution of search and switching costs. This can occur if insurers have incentives to engage in risk selection. In the Irish system evidence exists that risk equalisation may not be adequately reimbursing insurers for the risk they hold, therefore encouraging risk selection [36]. In Ireland risk selection is generally understood to take the form of targeting of preferred risk groups through, for example, advertising, marketing and product design [1]. If risk selection is taking place in the Irish market it is most likely accentuating the switching of more mobile, healthy risks.

7 Disinterest in plan comparison for very sick individuals could also be related to perceived high opportunity costs of time (i.e. a short life expectancy). In such instances, apathy may be considered a rational response, as it may not be in these individuals' interests to spend time comparing health insurance products. 
Table 6 Probit model of switching behaviour ${ }^{\mathrm{a}} \mathrm{b}$

\begin{tabular}{|c|c|c|c|}
\hline Variables & & $\begin{array}{l}\text { Coef. } \\
\text { (S.E) }\end{array}$ & $\begin{array}{l}\mathrm{dy} / \mathrm{dx} \\
(\mathrm{S} . \mathrm{E})\end{array}$ \\
\hline \multirow[t]{2}{*}{$\begin{array}{l}\text { Age } \\
18-44)\end{array}(\operatorname{Ref}=$} & $45-64$ & $\begin{array}{l}0.024 \\
(0.088)\end{array}$ & $\begin{array}{l}0.005 \\
(0.018)\end{array}$ \\
\hline & $65+$ & $\begin{array}{l}-0.286^{* *} \\
(0.124)\end{array}$ & $\begin{array}{l}-0.049^{* *} \\
(0.020)\end{array}$ \\
\hline Sex $\quad($ Ref $=$ Male $)$ & Female & $\begin{array}{l}0.119 \\
(0.081)\end{array}$ & $\begin{array}{l}0.023 \\
(0.016)\end{array}$ \\
\hline \multirow[t]{2}{*}{$\begin{array}{l}\text { Social Grade } \\
(R e f=A B C 1)\end{array}$} & $\mathrm{C} 2 \mathrm{DE}$ & $\begin{array}{l}0.084 \\
(0.087)\end{array}$ & $\begin{array}{l}0.016 \\
(0.017)\end{array}$ \\
\hline & $\mathrm{F}$ & $\begin{array}{l}0.061 \\
(0.145)\end{array}$ & $\begin{array}{l}0.012 \\
(0.029)\end{array}$ \\
\hline \multirow[t]{2}{*}{$\begin{array}{l}\text { Health Status } \\
(\text { Ref }=\text { Excellent })\end{array}$} & Good & $\begin{array}{l}-0.055 \\
(0.092)\end{array}$ & $\begin{array}{l}-0.011 \\
(0.018)\end{array}$ \\
\hline & Bad & $\begin{array}{l}-0.245^{* *} \\
(0.116)\end{array}$ & $\begin{array}{l}-0.044^{* *} \\
(0.019)\end{array}$ \\
\hline \multirow[t]{2}{*}{$\begin{array}{l}\text { Year of Survey } \\
(\text { Ref = 2009) }\end{array}$} & 2011 & $\begin{array}{l}0.451^{* * *} \\
(0.115)\end{array}$ & $\begin{array}{l}0.081^{* * *} \\
(0.021)\end{array}$ \\
\hline & 2013 & $\begin{array}{l}0.362^{* * *} \\
(0.104)\end{array}$ & $\begin{array}{l}0.061^{* * * *} \\
(0.016)\end{array}$ \\
\hline Constant & & $\begin{array}{l}-1.484^{* * *} \\
(0.114)\end{array}$ & \\
\hline Baseline switching & & $11.8 \%$ & \\
\hline Log-Likelihood & & -624.44 & \\
\hline
\end{tabular}

\subsection{Limitations}

Before concluding it is important to outline some limitations of this analysis. Particularly, this analysis was restricted somewhat by the nature of the survey data collected. Switching costs identified were determined by the motivations for consumer decision-making recorded in the surveys. For instance, it was not possible to identify the presence of benefit-loss or provider switching costs in the market. However, a priori it is unlikely that these costs represent major barriers to switching in the Irish market. Unlike other European systems, the voluntary Irish market is not structured in terms of basic and supplementary insurance (where in the Netherlands, benefit-loss represents a major switching cost [15]) while, as noted, selective contracting with providers is uncommon. Moreover, only minimal information was captured on actual switching behaviour which limited this aspect of the analysis. However, the associations identified did reflect previous, more detailed, findings on consumer switching in the Irish system [35]. It is also important to acknowledge that the study time horizon coincided with a period of significant economic turmoil in Ireland [37] which may impact on the interpretability of results. Finally, it was not possible to determine the impact insurer behaviour had on consumer-reported switching costs and this represents an potential avenue of future research. 


\section{Conclusion}

The analysis offers fresh empirical insights into consumer mobility in multipayer health insurance markets through examining the consumer-reported benefits and costs to switching health insurer. This study used the private health insurance market in Ireland as an environment to study these dynamics. Overall evidence suggests that switchers in the Irish market mainly did so out of consideration for price. This should encourage insurers in the market to compete along this dimension. However some potential barriers to switching were identified, with transaction costs the most frequently cited. In general consumer-reported switching costs were experienced more by high-risk individuals and this was also reflected in actual switching behaviour. A recent information campaign launched by the market regulator may prove beneficial in reducing perceived transaction costs in the market, however, a more focused campaign aimed at high-risk consumers may be necessary to reduce inequalities in the market. Policy-makers should also consider the impact insurer behaviour may have on consumer mobility.

Acknowledgements The authors would like to thank the HIA for access to their consumer survey data. This research was funded by the Health Research Board PHD/2007/16.

\section{Appendix}

8.1 Variance-covariance matrix of the cross-equation error terms reported in the multivariate probit model of switching costs (Table 5)

$\underline{\text { Equations excl. plan characteristics }}$

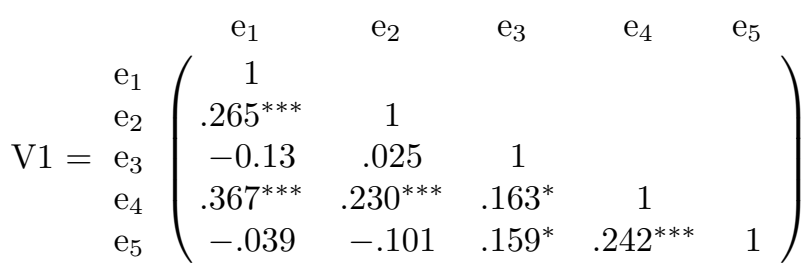

Likelihood ratio test that all correlation coefficients equal zero; $\chi^{2}(10)=$ $60.3298^{* * *}$

$\underline{\text { Equations incl. all variables }}$ 


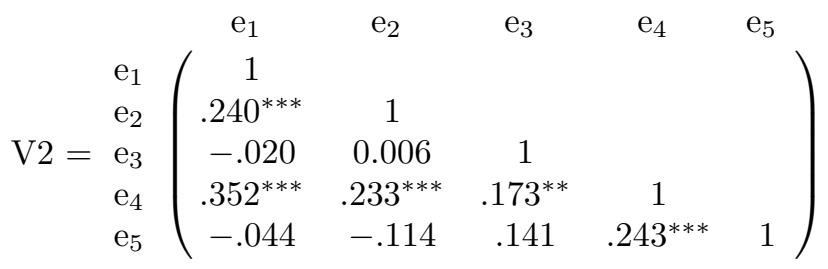

Likelihood ratio test that all correlation coefficients equal zero; $\chi^{2}(10)=$ $58.0019^{* * *}$

\section{References}

1. Armstrong, J.: Risk equalisation and voluntary health insurance markets: The case of Ireland. Health policy 98(1), 15-26 (2010)

2. Atherly, A., Florence, C., Thorpe, K.E.: Health plan switching among members of the Federal Employees Health Benefits Program. Inquiry : a journal of medical care organization, provision and financing 42(3), 255-265 (2005)

3. Bertakis, K.D., Azari, R., Helms, L.J., Callahan, E.J., Robbins, J.A.: Gender differences in the utilization of health care services. The Journal of family practice 49(2), 147-152 (2000)

4. Bevan, G., van de Ven, W.P.M.M.: Choice of providers and mutual healthcare purchasers: can the English National Health Service learn from the Dutch reforms? Health economics, policy, and law 5(3), 343-63 (2010)

5. Boonen, L.H.H.M., Donkers, B., Schut, F.T.: Channeling consumers to preferred providers and the impact of status quo bias: Does type of provider matter? Health Services Research 46(2), 510-530 (2011)

6. Boonen, L.H.H.M., Laske-Aldershof, T., Schut, F.T.: Switching health insurers: the role of price, quality and consumer information search. The European journal of health economics (2015)

7. Buchmueller, T.C.: The health plan choices of retirees under managed competition. Health services research 35(5 Pt 1), 949-76 (2000)

8. Buchmueller, T.C., Feldstein, P.J.: The effect of price on switching among health plans. Journal of health economics 16(2), 231-47 (1997)

9. Bundorf, M.K., Szrek, H.: Choice set size and decision making: the case of Medicare Part D prescription drug plans. Medical decision making 30(5), 582-593 (2010)

10. Cappellari, L., Jenkins, S.P.: The Stata Journal. The Stata Journal 3(3), pp.278-294 (2003)

11. Competition Authority: Competition in the Private Health Insurance Market. Tech. rep., The Competition Authority, Dublin (2007)

12. CSO: System of Health Accounts 2014 (2016). URL http://www.cso.ie/en/releasesandpublications/er/sha/systemofhealthaccounts2014/

13. Cummings, J.R., Rice, T., Hanoch, Y.: Who Thinks That Part D Is Too Complicated? Survey Results on the Medicare Prescription Drug Benefit. Medical care research and review 66(1), 97-115 (2009)

14. Cutler, D.M., J., R.S.: Paying for Health Insurance : The Trade-Off between Competition and Adverse Selection. The Quarterly Journal of Economics 113(2), 433-466 (1998)

15. Duijmelinck, D.M.I.D., Mosca, I., van de Ven, W.P.M.M.: Switching benefits and costs in competitive health insurance markets: A conceptual framework and empirical evidence from the Netherlands. Health policy 119(5), 664-71 (2015)

16. Duijmelinck, D.M.I.D., van de Ven, W.P.M.M.: Switching rates in health insurance markets decrease with age: empirical evidence and policy implications from the Netherlands. Health economics, policy, and law pp. 1-19 (2015) 
17. Farrell, J., Klemperer, P.: Coordination and Lock-In: Competition with Switching Costs and Network Effects. In: M. Armstrong, R. Porter (eds.) Handbook of Industrial Organization, vol. 2, chap. 31, pp. 1967-2072. Elsevier (2007)

18. Feldman, R., Finch, M., Dowd, B., Cassou, S.: The Demand for Employment-Based Health Insurance Plans. The Journal of Human Resources 24(1), 115 (1989). DOI $10.2307 / 145935$

19. Frank, R.G., Lamiraud, K.: Choice, price competition and complexity in markets for health insurance. Journal of Economic Behavior and Organization 71(2), 550-562 (2009)

20. Hanoch, Y., Rice, T., Cummings, J., Wood, S.: How much choice is too much? the case of the Medicare Prescription Drug Benefit. Health Services Research 44, 1157-1168 (2009)

21. Hartman, R.S., Doane, M.J., Woo, C.K.: Consumer Rationality and the Status Quo. The Quarterly Journal of Economics 106(1), 141-162 (1991)

22. HIA: The Private Health Insurance Market in Ireland. May, 2010. Tech. rep., The Health Insurance Authority, Dublin (2010). URL http://www.hia.ie/sites/default/files/RED C HIA Research Final Report wih summary 130510.pdf

23. HIA: Report on the Health Insurance Market: By Millward Brown Lansdowne to the Health Insurance Authority. Tech. rep., The Health Insurance Authority, Dublin (2012). URL http://www.hia.ie/publication/consumer-surveys/

24. HIA: Report to the Minister for Health on an evaluation and analysis of returns for 1 July 2013 to 30 June 2014 including advice on risk equalisation credits. Tech. rep., The Health Insurance Authority, Dublin (2014)

25. HIA: The Private Health Insurance Market in Ireland 2014. Tech. rep., The Health Insurance Authority, Dublin (2014). URL http://www.hia.ie/assets/files/publications/Consumer_surveys/HIA_Consumer Survey_2014_Final.pdf

26. HIA: Annual Report and Accounts 2015. Tech. rep., The Health Insurance Authority (2015). URL http://www.hia.ie/sites/default/files/HIA 2015 Annual Report English.pdf

27. HIA: Lifetime Community Rating Explained (2015). URL http://www.hia.ie/consumerinformation/lifetime-community-rating-explained

28. HIA: Switching Health Insurance Plan/Provider (2015). URL http://www.hia.ie/consumer-information/switching-health-insurance-plan-provider

29. HIA: Cancelling your Health Insurance Plan (2016). URL http://www.hia.ie/consumerinformation/cancelling-your-health-insurance-plan

30. HIA: Health Insurance Authority launches information campaign on policy renewals (2016). URL http://www.hia.ie/news/health-insurance-authority-launchesinformation-campaign-policy-renewals

31. HIA: Market Statistics 2015 (2016). URL http://www.hia.ie/publication/marketstatistics

32. Jacoby, J., Chestnut, R.W.: Brand Loyalty: Measurement and Management. Wiley and Sons, New York (1978)

33. de Jong, J.D., van den Brink-Muinen, A., Groenewegen, P.P.: The Dutch health insurance reform: switching between insurers, a comparison between the general population and the chronically ill and disabled. BMC health services research 8, 58 (2008)

34. Kahneman, D., Knetsch, J.L., Thaler, R.H.: Anomalies: The Endowment Effect, Loss Aversion, and Status Quo Bias. Journal of Economic Perspectives 5(1), 193-206 (1991)

35. Keegan, C., Teljeur, C., Turner, B., Thomas, S.: Switching insurer in the Irish voluntary health insurance market: determinants, incentives, and risk equalization. The European journal of health economics 17(7), 823-31 (2016). DOI 10.1007/s10198-015-0724-7. URL http://link.springer.com/10.1007/s10198-015-0724-7 http://www.ncbi.nlm.nih.gov/pubmed/26359243

36. Keegan, C., Teljeur, C., Turner, B., Thomas, S.: Addressing market segmentation and incentives for risk selection: How well does risk equalisation in the Irish private health insurance market work? Economic and Social Review 48(1), 61-84 (2017)

37. Keegan, C., Thomas, S., Normand, C., Portela, C.: Measuring recession severity and its impact on healthcare expenditure. International journal of health care finance and economics 13, 139-155 (2013) 
38. Klemperer, P.: Markets with Consumer Switching Costs. Quarterly Journal of Economics 102(2), 375-394 (1987)

39. Klemperer, P.: Competition When Consumers Have Switching Costs: An Overview with Applications to Industrial Organization, Macroeconomics, and International Trade. Review of Economic Studies 62(4), 515-539 (1995)

40. Kling, J.R., Mullainathan, S., Shafir, E., Vermeulen, L.C., Wrobel, M.V.: Comparison friction: experimental evidence from medicare drug plans. The quarterly journal of economics 127(1), 199-235 (2012)

41. Kolstad, J.T., Chernew, M.E.: Quality and consumer decision making in the market for health insurance and health care services. Medical care research and review 66(1 Suppl), 28S-52S (2009)

42. Krieger, M., Felder, S.: Can decision biases improve insurance outcomes? An experiment on status quo bias in health insurance choice. International journal of environmental research and public health 10(6), 2560-2577 (2013)

43. Lako, C.J., Rosenau, P., Daw, C.: Switching health insurance plans: results from a health survey. Health care analysis 19(4), 312-328 (2011)

44. Laske-Aldershof, T., Schut, E., Beck, K., Gress, S., Shmueli, A., Van de Voorde, C.: Consumer mobility in social health insurance markets : a five-country comparison. Applied health economics and health policy 3(4), 229-41 (2004)

45. Leukert-Becker, K., Zweifel, P.: Preferences for health insurance in Germany and the Netherlands - a tale of two countries. Health economics review 4, 22 (2014)

46. Nadash, P., Day, R.: Consumer choice in health insurance exchanges: can we make it work? Journal of health politics, policy and law 39(1), 209-35 (2014)

47. Nuscheler, R., Knaus, T.: Risk selection in the German public health insurance system. Health economics 14(12), 1253-71 (2005)

48. Oliver, R.L.: Whence Consumer Loyalty? Journal of Marketing 63, 33-44 (1999)

49. Patterson, P.G.: Demographic correlates of loyalty in a service context. Journal of Services Marketing 21(2), 112-121 (2007)

50. Pendzialek, J.B., Danner, M., Simic, D., Stock, S.: Price elasticities in the German Statutory Health Insurance market before and after the health care reform of 2009 . Health policy 119(5), 654-63 (2015)

51. Reitsma-van Rooijen, M., de Jong, J.D., Rijken, M.: Regulated competition in health care: switching and barriers to switching in the Dutch health insurance system. BMC health services research 11(95) (2011)

52. Royalty, A.B., Solomon, N.: Health Plan Choice : Price Elasticities in a Managed Competition Setting Health Plan Choice Price Elasticities in a Managed Competition Setting. The Journal of Human Resources 34(1), 1-41 (1999)

53. Samuelson, W., Zeckhauser, R.: Status Quo Bias in Decision Making. Journal of Risk and Uncertainty 1, 7-59 (1988)

54. Schut, F.T., Hassink, W.H.J.: Managed competition and consumer price sensitivity in social health insurance. Journal of health economics 21(6), 1009-29 (2002)

55. Shi, M.: A theoretical analysis of endogenous and exogenous switching costs. Quantitative Marketing and Economics 11(2), 205-230 (2013)

56. Shmueli, A., Bendelac, J., Achdut, L.: Who switches sickness funds in Israel? Health economics, policy, and law 2, 251-65 (2007)

57. Tanius, B.E., Wood, S., Hanoch, Y.: Aging and choice : Applications to Medicare Part D. Judgement and Decision Making 4(1), 92-101 (2009)

58. Thomson, S., Busse, R., Crivelli, L., van de Ven, W., Van de Voorde, C.: Statutory health insurance competition in Europe: a four-country comparison. Health policy 109(3), 209-25 (2013)

59. Turner, B., Shinnick, E.: Community rating in the absence of risk equalisation: lessons from the Irish private health insurance market. Health Economics, Policy and Law 8(2), 209-224 (2013)

60. Weintraub, E.R.: Neoclassical economics (2007) http://www.econlib.org/library/Enc1/NeoclassicalEconomics.html

61. Wilson, C.M.: Markets with Search and Switching Costs (2007). URL http://www.uea.ac.uk/polopoly_fs/1.104487!ccp06-10.pdf 